Article

\title{
Spectral Analysis and Sensitive Waveband Determination Based on Nitrogen Detection of Different Soil Types Using Near Infrared Sensors
}

\author{
Shupei Xiao ${ }^{1,2}$, Yong He ${ }^{1,2, *(\mathbb{D})}$, Tao Dong ${ }^{1,2}$ and Pengcheng Nie ${ }^{1,2,3}$ \\ 1 College of Biosystems Engineering and Food Science, Zhejiang University, Hangzhou 310058, China; \\ 180312@zju.edu.cn (S.X.); dt2016@zju.edu.cn (T.D.); npc2012@zju.edu.cn (P.N.) \\ 2 Key Laboratory of Spectroscopy Sensing, Ministry of Agriculture, Zhejiang University, \\ Hangzhou 310058, China \\ 3 State Key Laboratory of Modern Optical Instrumentation, Zhejiang University, Hangzhou 310058, China \\ * Correspondence: yhe@zju.edu.cn; Tel.: +86-0571-8898-2143
}

Received: 18 December 2017; Accepted: 5 February 2018; Published: 9 February 2018

\begin{abstract}
Compared with the chemical analytical technique, the soil nitrogen acquisition method based on near infrared (NIR) sensors shows significant advantages, being rapid, nondestructive, and convenient. Providing an accurate grasp of different soil types, sensitive wavebands could enhance the nitrogen estimation efficiency to a large extent. In this paper, loess, calcium soil, black soil, and red soil were used as experimental samples. The prediction models between soil nitrogen and NIR spectral reflectance were established based on three chemometric methods, that is, partial least squares (PLS), backward interval partial least squares (BIPLS), and back propagation neural network (BPNN). In addition, the sensitive wavebands of four kinds of soils were selected by competitive adaptive reweighted sampling (CARS) and BIPLS. The predictive ability was assessed by the coefficient of determination $R^{2}$ and the root mean square error (RMSE). As a result, loess $(0.93<$ $\left.R_{p}^{2}<0.95,0.066 \mathrm{~g} / \mathrm{kg}<\mathrm{RMSE}_{p}<0.075 \mathrm{~g} / \mathrm{kg}\right)$ and calcium soil $\left(0.95<R_{p}^{2}<0.96,0.080 \mathrm{~g} / \mathrm{kg}<\right.$ $\mathrm{RMSE}_{p}<0.102 \mathrm{~g} / \mathrm{kg}$ ) achieved a high prediction accuracy regardless of which algorithm was used, while black soil $\left(0.79<R_{p}^{2}<0.86,0.232 \mathrm{~g} / \mathrm{kg}<\mathrm{RMSE}_{p}<0.325 \mathrm{~g} / \mathrm{kg}\right)$ obtained a relatively lower prediction accuracy caused by the interference of high humus content and strong absorption. The prediction accuracy of red soil $\left(0.86<R_{p}^{2}<0.87,0.231 \mathrm{~g} / \mathrm{kg}<\mathrm{RMSE}_{p}<0.236 \mathrm{~g} / \mathrm{kg}\right)$ was similar to black soil, partly due to the high content of iron-aluminum oxide. Compared with PLS and BPNN, BIPLS performed well in removing noise and enhancing the prediction effect. In addition, the determined sensitive wavebands were $1152 \mathrm{~nm}-1162 \mathrm{~nm}$ and $1296 \mathrm{~nm}-1309 \mathrm{~nm}$ (loess), $1036 \mathrm{~nm}-1055 \mathrm{~nm}$ and $1129 \mathrm{~nm}-1156 \mathrm{~nm}$ (calcium soil), $1055 \mathrm{~nm}, 1281 \mathrm{~nm}, 1414 \mathrm{~nm}-1428 \mathrm{~nm}$ and $1472 \mathrm{~nm}-1493 \mathrm{~nm}$ (black soil), $1250 \mathrm{~nm}, 1480 \mathrm{~nm}$ and $1680 \mathrm{~nm}$ (red soil). It is of great value to investigate the differences among the NIR spectral characteristics of different soil types and determine sensitive wavebands for the more efficient and portable NIR sensors in practical application.
\end{abstract}

Keywords: soil nitrogen; NIR sensors; sensitive wavebands; PLS; BIPLS; BPNN; CARS

\section{Introduction}

Soil is the main resource supporting crop nutrients, and its spectral reflection characteristics are some of the most important features relating to its physical and chemical properties. The nitrogen content of soil directly influences the crop growth status, which is an important reference factor for crop growth estimation [1,2]. NIR spectroscopy is a common analytical method with the advantages of fast analysis speed, simple sample pretreatment, easy operation, and low cost. Compared with 
the traditional analytical technique, the application of NIR sensors to estimate soil nitrogen content accurately and rapidly shows a greater advantage and a wider application prospect [3-5].

Domestic and foreign scholars have explored the effects of soil water content, organic matter, nitrogen, phosphorus, potassium, texture, surface roughness, and $\mathrm{pH}$ value on soil nitrogen detection. Demattê et al. [6] used a laboratory spectroradiometer (450-2500 nm) to determine soil classes (collected from São Paulo State) by evaluating the spectral reflectance curves at different depths, and found that organic matter, total iron, silt, sand, and mineralogy were the primary factors influencing spectral intensity and characteristics. Shao et al. [7] applied least-squares support vector machines (LS-SVM) to construct calibration models for soil properties such as available nitrogen $(\mathrm{N})$, phosphorus $(\mathrm{P})$, and potassium $(\mathrm{K})$, whose correlation coefficients of the prediction set were $0.90,0.88$, and 0.89 , respectively. He et al. [8] used the NIR sensors to estimate the N, P, K, organic matter $(\mathrm{OM})$ and $\mathrm{pH}$ content in a loamy mixed soil which were then analyzed by principal component analysis and partial least square. The results showed that the correlation coefficient between measured and predicted values of $\mathrm{N}, \mathrm{OM}$, and $\mathrm{pH}$ were $0.93,0.93$, and 0.91 , respectively, but $\mathrm{P}$ and $\mathrm{K}$ could not be predicted.

Moreover, some researchers have demonstrated the strong correlation between soil properties and spectral reflectance characteristics using different analytical methods. Aitkenhead et al. [9] predicted the chemical and physical properties of soil by an established neural network model compared to the national soil database of Scotland. The inputs of the prediction model included soil color, texture classification, and site information while the outputs were soil organic matter, magnesium, calcium and nickel content, total alkali saturation, and $\mathrm{pH}$ value. The results showed that organic matter, $\mathrm{Mg}$, $\mathrm{Ca}, \mathrm{Ni}$, total base saturation, and $\mathrm{pH}$ were predicted with a high degree of accuracy. Gao et al. [10] adopted successive projection algorithms to analyze 85 soil samples after contribution values and six characteristic wavelength values were obtained. The correlation coefficient of the prediction set was 0.913 and the prediction root mean square error (RMSEP) was $0.011 \%$. Rinnan et al. [11] tested the applicability of NIR spectroscopy and fluorescence spectroscopic techniques in analyzing the chemical and microbial characteristics of soil during a long-term climate change manipulation experiment. The results suggested that the chemical composition and spectral properties of soil changed with the variation of the climate situation and NIR spectroscopy could be used to detect soil organic matter and fungal biomass.

In addition, the accurate determination of sensitive wavebands based on different soil types helps to improve the detection efficiency to a large extent. Zhang et al. [12] determined six sensitive wavebands $(1375,1520,1861,2100,2286$, and $2387 \mathrm{~nm})$ for predicting the soil's total nitrogen content using combined wavelet analysis and continuum removal technology, which achieved great accuracy in predicting the soil's total nitrogen content in real time. Pan et al. [13] selected the sensitive wavebands of the NIR spectral range from $1692 \mathrm{~nm}$ to $2138 \mathrm{~nm}$ using moving window partial least square (MWPLS) and Savitzky-Golay (S-G) smoothing methods. The correlation coefficient of the modeling set was 0.931 and the correlation coefficient of the validating set was 0.882 . Dalal et al. [14] determined the best prediction waveband of soil moisture, organic carbon, and total nitrogen using NIR diffuse reflectance spectrophotometry (1100-2500 nm) combined with multiple regression analysis. It was found that the soil's total nitrogen characteristic wavebands were 1702, 1870, and $2052 \mathrm{~nm}$. Lu et al. [15] analyzed the spectral reflectance variation of black soil in Northeast China between 350 and $2500 \mathrm{~nm}$ by the reflectance logarithm of the first derivative spectrum, and determined that the optimum prediction model of black soil total nitrogen content and the selected bands were 556, 1642, and $2491 \mathrm{~nm}$, whose $R^{2}$ was 0.863 and RMSE was $0.122 \mathrm{~g} / \mathrm{kg}$.

The objective of this study was to compare the influences of soil types and modeling methods on soil nitrogen detection by NIR sensors as well as determine the optimum sensitive wavebands of four kinds of soils. In addition, it was to investigate the potential of replacing full wavebands by sensitive wavebands in soil nitrogen prediction, which is helpful for improving the overall detection efficiency and developing more efficient and professional instruments for soil nitrogen detection. 


\section{Materials and Methods}

\subsection{Experimental Materials}

The experimental materials included loess, calcium soil, black soil, and red soil collected from various regions, whose nitrogen content differs from each other, which is of great credibility to investigate the difference of NIR spectra taking those four kinds of soils for experimental samples. The loess was collected from Xi'an $\left(34^{\circ} 27^{\prime} \mathrm{N}, 108^{\circ} 95^{\prime} \mathrm{E}\right.$, Shaanxi province, China), and was mainly comprised of detrital mineral (including quartz, feldspar, and carbonate mineral) and clay mineral. The proportion of coarse particles $(0.05-0.01 \mathrm{~mm})$ in loess is more than $50 \%$ with high carbonate content, and the content of organic matter and nitrogen in loess is relatively low due to geographical distribution. The calcium soil was collected from Jining $\left(35^{\circ} 23^{\prime} \mathrm{N}, 116^{\circ} 33^{\prime} \mathrm{E}\right.$, Shandong province, China), and contained a certain amount of organic matter and ash with high carbonate content (calcium carbonate and magnesium carbonate). The soil texture was loose and the humus layer was thick. The black soil was collected from the Greater Khingan Mountains ( $46^{\circ} 08^{\prime} \mathrm{N}, 122^{\circ} 05^{\prime} \mathrm{E}$, Inner Mongolia Autonomous Region, China), and was neutral or slightly alkaline with organic content between 3\% and $10 \%$. The black soil mainly included calcareous sedimentary rock, basic igneous rock, basalt, and volcanic ash, resulting in the characteristics of having high organic matter as well as being one of the most fertile soils in China. The red soil was collected from Lishui $\left(27^{\circ} 62^{\prime} \mathrm{N}, 119^{\circ} 05^{\prime} \mathrm{E}\right.$, Zhejiang province, China), having the characteristics of high water content, low density, and high intensity. It was mainly comprised of carbonate and rock rich in iron-aluminum oxides weathered in the hot and humid climate.

The sample preparation process was as follows: First, the four kinds of soils were all collected from the surface layer 0-20 cm from the ground, and were sieved with a 40 -mesh sieve $(0.425 \mathrm{~mm})$. Second, the urea solutions with different nitrogen concentrations were prepared and mixed with soil samples where the nitrogen concentration ranges were loess $(0.09-0.93 \mathrm{~g} / \mathrm{kg}, 176 \mathrm{samples})$, calcium soil (0.33-1.17 g/kg, 176 samples), black soil (0.47-2.15 g/kg, 176 samples) and red soil (0.47-2.10 g/kg, 144 samples). Meanwhile, the four kinds of soils without urea added were set as references. Third, all soil samples were compressed into slices by an acrylic plate (PMMA) and divided into easily detectable sizes, then dried in an oven at 80 degrees Celsius for $24 \mathrm{~h}$ in order to eliminate the interference of soil moisture on NIR spectra.

\subsection{NIR Spectrum Collection}

The characteristic signal of the NIR spectral region can reflect the main structure and composition of various organic compounds with the advantages of being stable and easy to handle [16,17]. The NIR spectrum collection experiment used a portable NIR optical spectrum instrument (NIRez) from Isuzu Optics Corp (Shanghai, China), which is reflective with two integrated tungsten halogen lamps. This instrument collects spectral information in the range of 900-1700 nm; its optical resolution is $10 \mathrm{~nm}$, and the signal-noise ratio is 5000:1 in a one-second scan. Before performing the spectral determination, the instrument should be preheated for $15 \mathrm{~min}$ and be prepared with blackboard and whiteboard correction operations. During the spectrum acquisition process, the spectral scan range, scale rate, and scan times can be set as required, and the information about intensity, reflectance, and absorbance of the spectrum can be collected. This experiment collected 400 points of each spectrum and obtained a spectral image at an average of 3 times per scan. In this experiment, 672 soil samples of four kinds of soils were measured in total.

\subsection{Preprocessing of Spectral Data}

Savitzky-Golay (S-G) smoothing was used to preprocess the raw spectral data in this experiment, quantizing the spectral data in the moving window by polynomial least squares fitting as well as emphasizing the central role of the center point. The formula of average wavelengths after S-G smoothing is $[18,19]$ : 


$$
x_{k, \text { smooth }}=\overline{x_{i}}=\frac{1}{H} \sum_{i=-w}^{+w} x_{k+1} h i
$$

where $H$ is the normalization factor, $h i$ is the smoothing coefficient, and $H=\sum_{I=-W}^{+W} h_{i}$. The measured value multiplied by the smoothing coefficient is to minimize the smoothing influence on the useful information. In this experiment, the original NIR spectra were processed with 9-point S-G smoothing.

\subsection{Chemometrics Methods}

In this experiment, three chemometric methods (PLS, BIPLS, BPNN) were used to establish the prediction model between soil nitrogen content and NIR spectra. Standard Normal Variation (SNV) was also included to correct the baseline in PLS, BIPLS, and BPNN, whose principle is that the absorbance values of each wavelength point satisfy a certain distribution in each spectra, and the spectral correction is performed according to this assumption [20]. In addition, the sensitive wavebands of four types of soils were determined by CARS and BIPLS. In this paper, all data analysis was based on MATAB R2014a (The Math-Works, Natick, MA, USA).

\subsubsection{Partial Least Squares}

Partial least squares (PLS) is a regression modeling method of multi-dependent variables to multi-independent variables, which extracts the most comprehensive variables and identifies the noise by decomposing and filtering the data in the system. When there is a high correlation within each set of variables, PLS can compare multiple variables by multiple regression to establish a more reliable model [21,22]. When PLS is applied to the spectral data model, the spectral matrix is decomposed first, the main principal component variables are obtained, and the contribution rate of each principal component is calculated. Based on the accumulative contribution rate of principal components, the first few principal components are selected as input to establish a mapping relationship with chemical indicators. Generally, the flexibility of PLS makes it possible to establish a regression model in the case where the number of samples is less than the number of variables, which is one of the least restrictive methods in the multivariate correction method [23].

\subsubsection{Backward Interval Partial Least Squares}

Backward interval partial least squares (BIPLS) is a variable selection method mainly used to filter the wavelength range of the PLS model and reduce the amount of sub-intervals of the worst or collinear variables. It selects the best principal component number according to the root mean square error of cross validation (RMSECV) [24,25]. The algorithm steps are mainly as follows:

1. Divide the whole spectrum into $\mathrm{k}$ bands of equal width;

2. Reserve a section from the k section spectrum, carry out PLS regression on the remaining (k-1) section, and establish the sub-model of the quality to be measured. Set aside each paragraph in order to get the k sub-model;

3. Evaluate the precision of each model through the RMSECV value, delete the reserved segment according to the sub-model with the highest precision, and take the sub-model as the first base model;

4. Leave one more section in the remaining (k-1) section of the spectrum and use the remaining (k-2) segments to model the PLS. Each section is set aside in order to obtain the (k-1) sub-model to remove the reserved segments corresponding to the sub-model of the minimum RMSECV value; take the sub-model as the second base model. Repeat the above process until there is a remaining waveband.

5. Examine the RMSEP value of each base model according to steps 2 to 4 , select the best and minimum RMSECV among all the base models, and the corresponding interval combination is the best combination. 


\subsubsection{Back Propagation Neural Network}

The back propagation neural network (BPNN) is a supervised learning algorithm in an artificial neural network (ANN) [26]. It is a multilayer feedforward network which corrects the weights by the error propagation algorithm. The ANN model simulates the neural structure of the brain based on the processing network of large numbers of processing units to train and model the data. The basic idea of the BPNN algorithm is to iteratively optimize the weight of the network and establish the mapping relationship between the dependent variables and the independent variables [27]. It calculates the error of each layer by calculating the error of each unit and adjusts the weights by the gradient descent algorithm, in order to improve the training speed and obtain the optimum objective function. In addition, the BPNN algorithm can approximate the arbitrary function in theory. Its basic structure is composed of non-linear variable elements; it has a strong nonlinear mapping ability, learning adaptability, and fault tolerance, and has a wide application prospect in data mining and artificial intelligence.

\subsubsection{Competitive Adaptive Reweighted Sampling}

Competitive adaptive reweighted sampling (CARS) is a feature wavelength selection method based on Monte Carlo sampling and the PLS regression coefficient, which eliminates the unadapted wavelength variables by the random sampling method [28]. This algorithm chooses part of the samples in the total sample set to carry out PLS modeling, and in the process of iterating over hundreds of times, only the wavelength variables with a large absolute value for the PLS regression coefficient remained and the wavelength variables with a small absolute value for the PLS regression coefficient were removed, aiming to obtain a part of the optimal wavelength variable subset [29]. In this experiment, CARS was used to select the characteristic variables for the further determination of sensitive wavebands.

\subsection{SPXY Method}

SPXY is the abbreviation of sample set partitioning based on joint $x-y$ distance, which was put forward by Galvao et al [30] based on (Kennard-Stone)K-S methods. The basic idea of this method is to consider the spectral characteristics and physicochemical properties at the same time by calculating the distance between the samples. The distance formula is as follows:

$$
\begin{gathered}
d_{x y}=\frac{d_{x}(i, j)}{\max _{i, j \in(i, j)}\left[d_{x}(i, j)\right]}+\frac{d_{y}(i, j)}{\max _{i, j \in(i, j)}\left[d_{y}(i, j)\right]}, i, j \\
\in[1, z]
\end{gathered}
$$

where $d_{x}(i, j)$ refers to the spectral characteristic parameters for the calculation of the distance between the samples while $d_{y}(i, j)$ refers to concentration characteristic parameters for the calculation of the distance between the samples. The $d_{x}(i, j)$ and $d_{y}(i, j)$ were divided by their corresponding maximum values, which makes the sample in spectrum space and concentration space have the same weightiness. $\mathrm{z}$ is the spectral space.

\subsection{Model Evaluation Index}

In this experiment, the modeling effect was evaluated by the coefficient of determination $R^{2}$ and the root mean square error (RMSE). The coefficient of determination $R^{2}$ reflects the level of intimacy between variables while the RMSE reflects the accuracy of the model. The closer the $R^{2}$ to 1 and the closer the RMSE to 0 , the better the performance of the prediction model. In this paper, $R_{c}^{2}$ and $R_{p}^{2}$ represent the coefficient of determination of the calibration set and the prediction set, respectively. $\mathrm{RMSE}_{c}$ and $\mathrm{RMSE}_{p}$ represent the root mean square error of the calibration set and the prediction set, respectively. In addition, all data processing was based on MATLAB R2014a (The Math-Works, Natick, MA, USA). 


\section{Results and Discussion}

\subsection{Analysis of Soil NIR Spectrum}

This study collected the NIR spectra of four kinds of soils by a portable NIR sensor. The original spectral curves of the four kinds of soils are shown in Figure 1 while the average spectral curves preprocessed by the S-G smoothing of the four kinds of soils at different nitrogen concentrations are shown in Figure 2. The abscissa is the wavelength and the ordinate is the spectral reflectance, and each curve represents the variation in the average spectral reflectance of the soil sample with the wavelength at a certain nitrogen concentration.
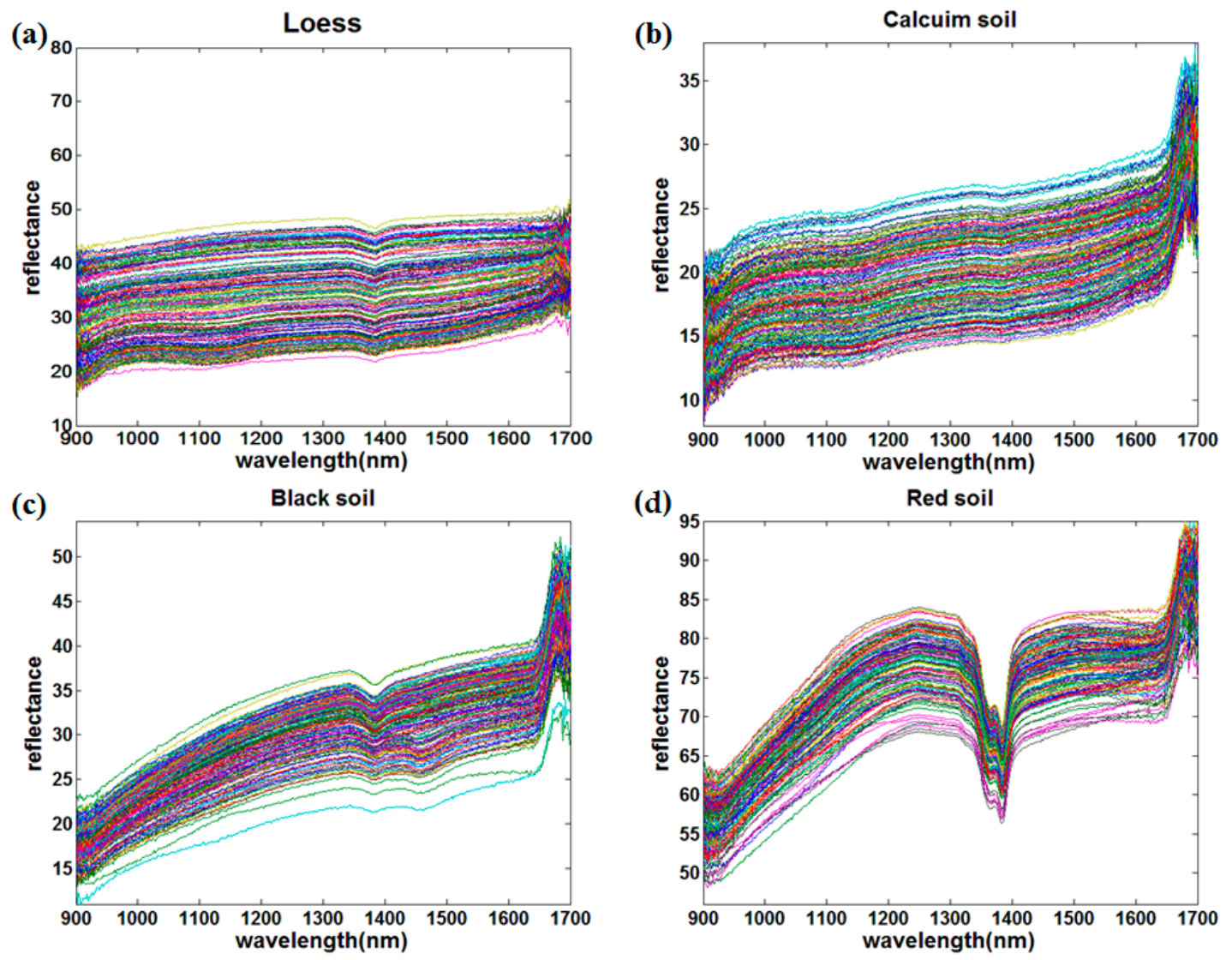

Figure 1. The original near infrared (NIR) curves of four kinds of soils. (a) Loess; (b) Calcium soil; (c) Black Soil; (d) Red soil.

Comparing the original and average spectra of the four kinds of soils, there are many differences in the peak, reflectance, and dispersion degree. First, the absorption peaks of the red soils were the most obvious in the range of $1350 \mathrm{~nm}$ to $1380 \mathrm{~nm}$, followed by black soil and loess, while the absorption peak of the calcium soil was the weakest. Second, the dispersion degree of spectral curves from large to small were loess, calcium soil, red soil, and black soil. Third, there were also large differences in reflectance among the different types of soils using NIR spectroscopy. The reflectance of loess and calcium soil changed slightly within the whole wavelength range, where the reflectance of loess was in the range of 15 to 45 and the calcium soil was 10 to 35. In addition, the reflectance increased slowly with the increase of soil nitrogen concentrations and wavelength, where the reflectance of the same soil nitrogen concentration curve increased by only 10 within the whole wavelength range, which was similar to calcium soil. The reflectance of black soil and red soil changed significantly, where the variation range was 15 to 50 and 55 to 90, respectively. Although the reflectance range of black soil was similar to that of loess, the reflectance increasing extent of the same curve within the whole wavelength range was much larger than that of the loess, which was around 30. The reflectance of red 
soil was in the range of 55 to 90, which was the highest among the four soil types, and its overall trend was similar to that of black soil.

(a)

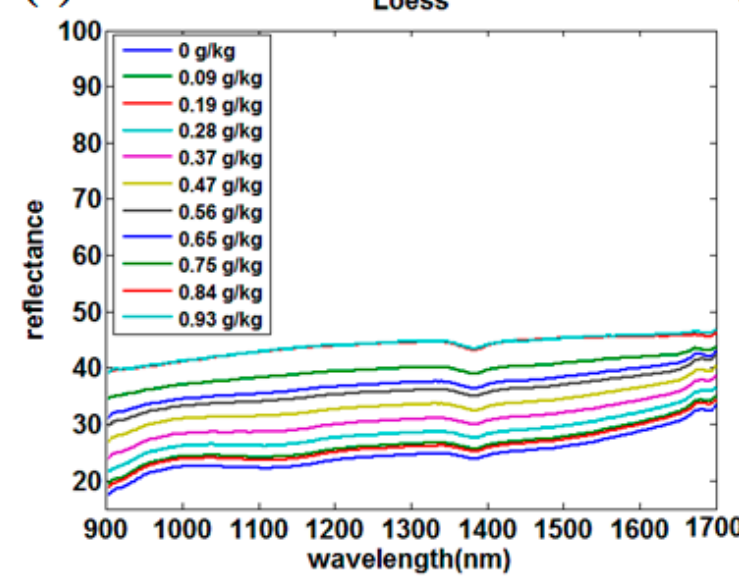

(c)

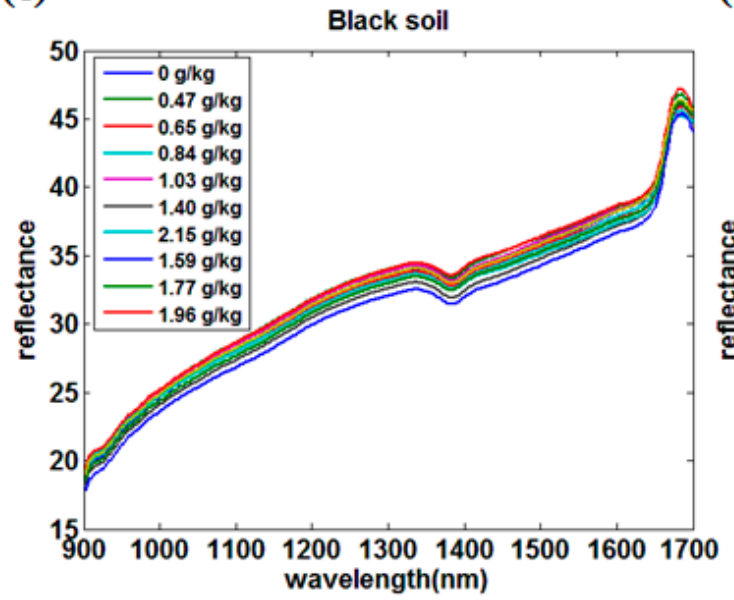

(b)

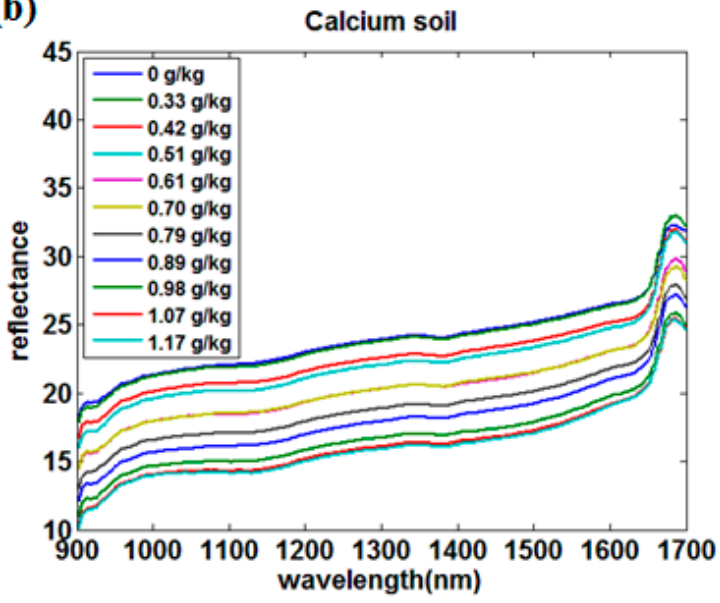

(d)

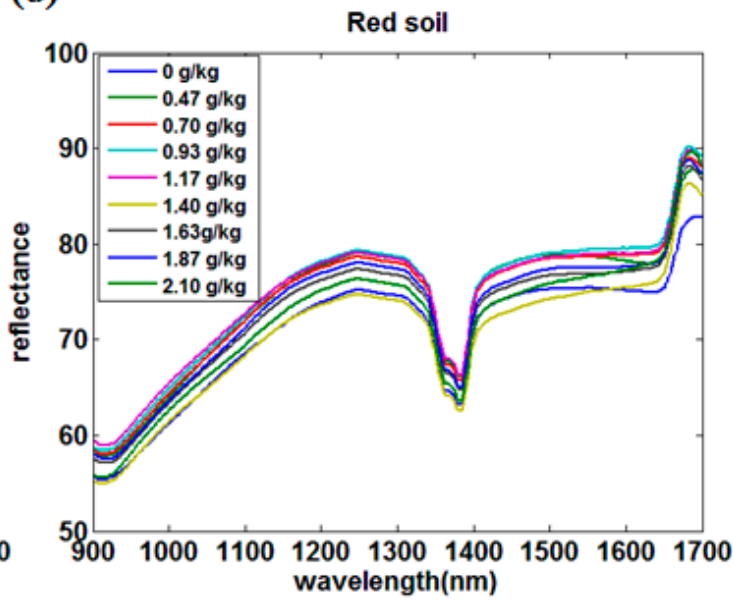

Figure 2. The average NIR spectral curves of four kinds of soils at each nitrogen concentration. (a) Loess;

(b) Calcium soil; (c) Black Soil; (d) Red soil.

\subsection{Full-Waveband Data Analysis and Modeling}

In this experiment, three chemometric methods were used to establish the prediction models between soil nitrogen content and the NIR spectrum. The four kinds of soil samples were divided into two groups according to the ratio of the calibration set and the prediction set of 2:1 using the SPXY method.

\subsubsection{Partial Least Squares}

In this experiment, the NIR spectral matrix was the independent variable $X$, and the soil nitrogen concentration was the dependent variable Y. Figure 3 presents the prediction performance of the four kinds of soils by PLS.

PLS is the most commonly used chemometrics modeling method, which has the least restrictive conditions during usage. In the process of PLS modeling, when the noise of the NIR spectrum has a great influence on the selection of principal components, the prediction performance is largely influenced by soil properties. Zhang et al. [31] analyzed the relationship between the total nitrogen content and the NIR spectral reflectance of five soil types (paddy soil, fluvo-aquic soil, salinized fluvo-aquic soil, saline soil, and black soil with lime concretion), where black soil with 
lime concretion and salinized fluvo-aquic soil showed the worst prediction performance. In our results, the PLS prediction models of loess, calcium soil, and red soil achieved a good effect, especially loess $\left(R_{p}^{2}=0.95, \mathrm{RMSE}_{p}=0.066 \mathrm{~g} / \mathrm{kg}\right)$ and calcium soil $\left(R_{p}^{2}=0.96, \mathrm{RMSE}_{p}=0.080 \mathrm{~g} / \mathrm{kg}\right)$. The prediction accuracy of black soil $\left(R_{p}^{2}=0.79, \mathrm{RMSE}_{p}=0.236 \mathrm{~g} / \mathrm{kg}\right)$ was lower than that of the other three soils, which was consistent with Zhang's research results. The reason might be that the absorption of the organic matter in black soil is strong, which has a certain influence on both the NIR spectrum and the selection of the principal component.

(a)

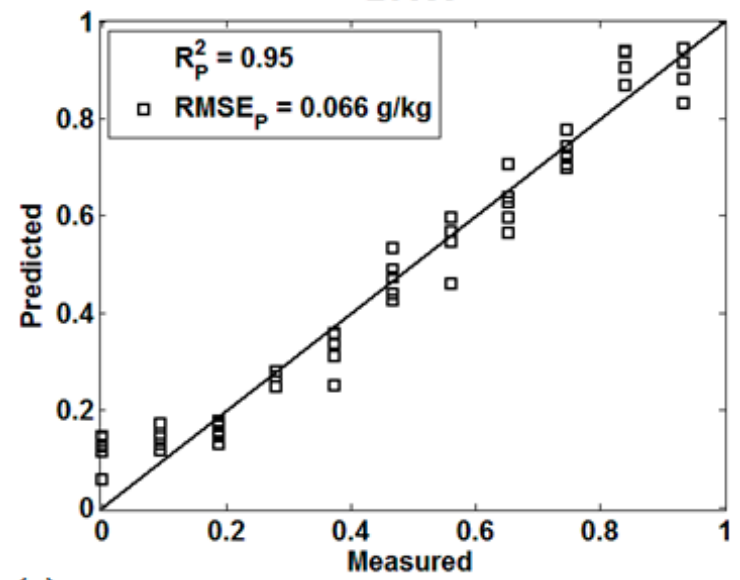

(c)

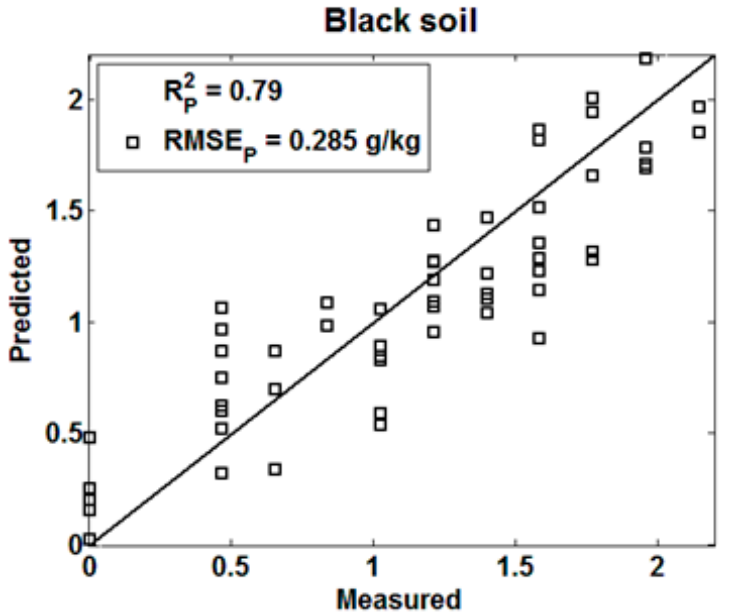

(b)

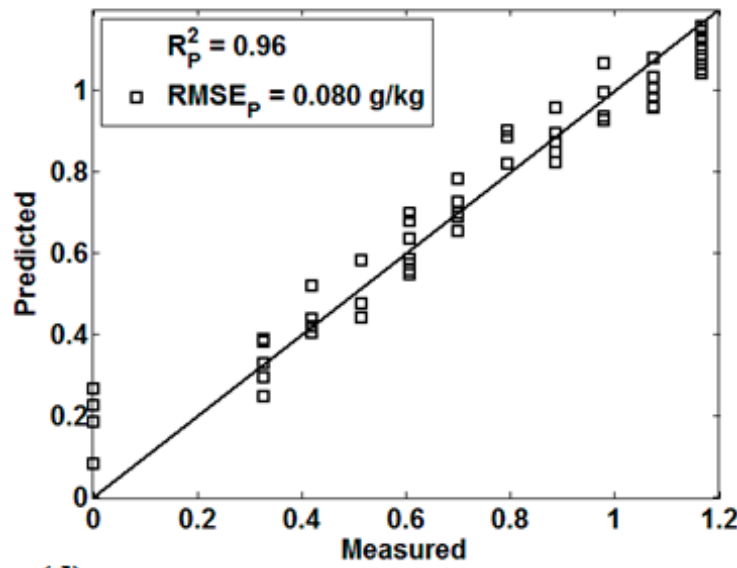

(d)

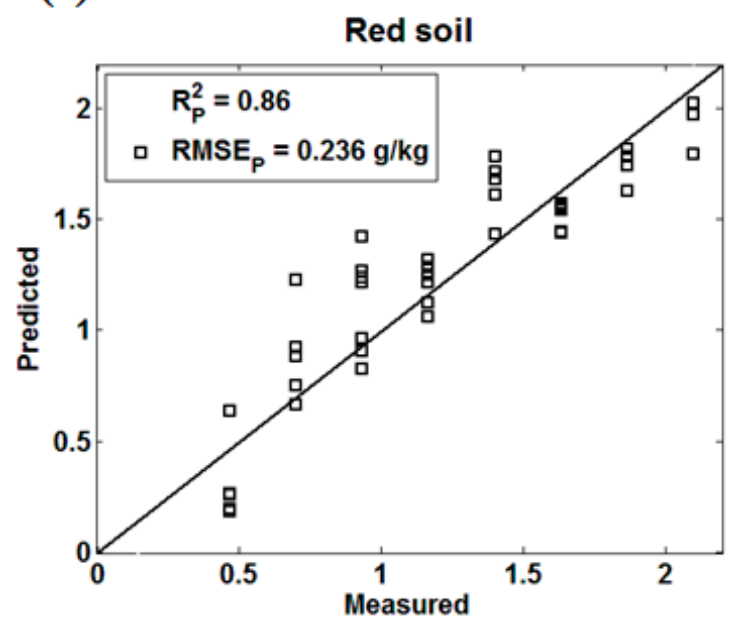

Figure 3. The Partial Least Squares (PLS) effect of four kinds of soils. (a) Loess; (b) Calcium soil; (c) Black Soil; (d) Red soil.

\subsubsection{Backward Interval Partial Least Squares}

Backward interval partial least squares is based on the interval least squares, which removes the maximum interval of RMSECV and establishes the optimal PLS model based on the remaining interval. When the RMSECV is the smallest and the corresponding interval is the optimized combination, the model with poor information can optimize the modeling effect to a certain extent for the collinearity variable. The prediction effect of four kinds of soils by BIPLS was shown in Figure 4.

Loess $\left(R_{p}^{2}=0.94, \mathrm{RMSE}_{p}=0.075 \mathrm{~g} / \mathrm{kg}\right)$, calcium soil $\left(R_{p}^{2}=0.95, \mathrm{RMSE}_{p}=0.081 \mathrm{~g} / \mathrm{kg}\right)$, and red soil $\left(R_{p}^{2}=0.86, \operatorname{RMSE}_{p}=0.231 \mathrm{~g} / \mathrm{kg}\right)$ displayed a similar prediction performance as well as those in PLS models. However, the black soil $\left(R_{p}^{2}=0.86, \mathrm{RMSE}_{p}=0.232 \mathrm{~g} / \mathrm{kg}\right)$ with poor prediction accuracy in PLS achieved a better result using the BIPLS algorithm, which suggested that the BIPLS 
algorithm might be able to eliminate the interference noise caused by the strong absorption of black soil and reduce the collinear variables to enhance the prediction accuracy.

(a)

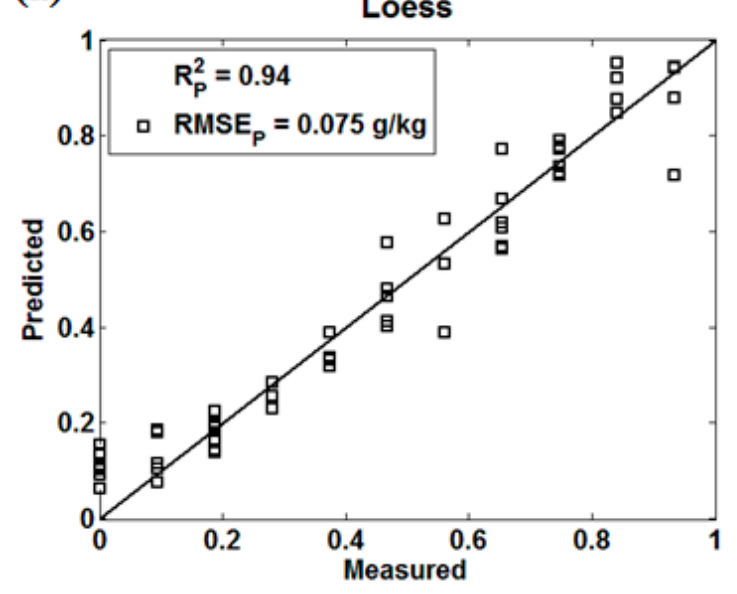

(c)

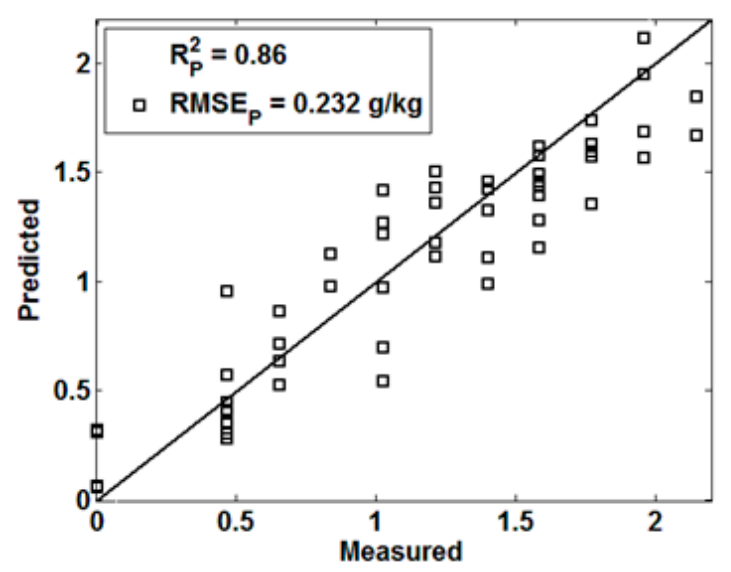

(b)

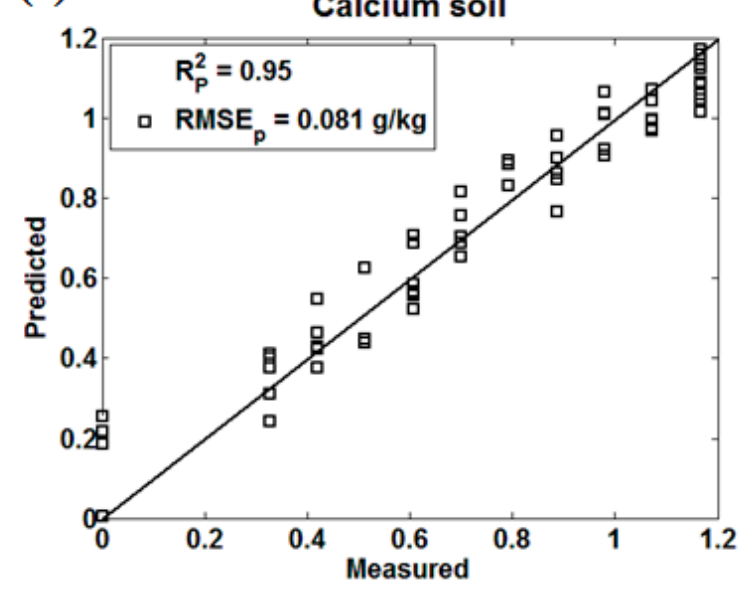

(d)

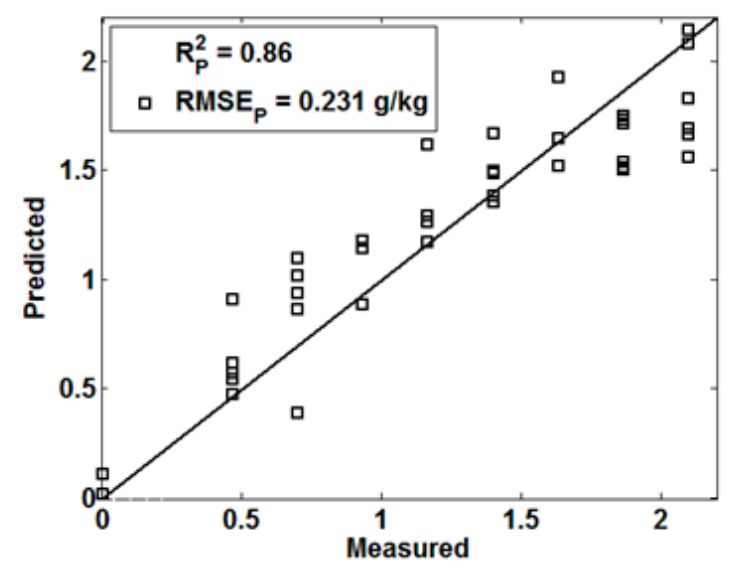

Figure 4. The Backward Interval Partial Least Squares (BIPLS) effect of four kinds of soils (a) Loess;

(b) Calcium soil; (c) Black Soil; (d) Red soil.

\subsubsection{Back Propagation Neural Network}

Back Propagation Neural Network is the most representative and widely used neural network, with the advantages of a simple structure and strong operability, and it can simulate arbitrary nonlinear input and output relations. Figure 5 presents the prediction effect of four kinds of soils by the BPNN model.

In this algorithm, the mapminmax function was used to normalize and de-normalize the BP neural network model of 3-layer network topology. The tansig function was used as the hidden layer transfer function, purelin was the output layer function and trainlm was the training function [32]. The learning rate was set as 0.1 , the maximum number of training times was 1000, and the model expectation error was 0.00005 . While running this algorithm, the iteration number was set at 100 times, considering both the modeling effect and algorithm running efficiency.

Loess $\left(R_{p}^{2}=0.93, \operatorname{RMSE}_{p}=0.075 \mathrm{~g} / \mathrm{kg}\right)$, calcium soil $\left(R_{p}^{2}=0.95, \mathrm{RMSE}_{p}=0.102 \mathrm{~g} / \mathrm{kg}\right)$, black soil $\left(R_{p}^{2}=0.79, \operatorname{RMSE}_{p}=0.325 \mathrm{~g} / \mathrm{kg}\right)$, and red soil $\left(R_{p}^{2}=0.87, \mathrm{RMSE}_{p}=0.231 \mathrm{~g} / \mathrm{kg}\right)$ all achieved similar prediction effects in BPNN models as well as those in PLS models. The BPNN algorithm has a strong nonlinear mapping ability to approach the best objective function, but fails to eliminate the interference information before training and modelling [27]. The results indicated that both PLS and 
BPNN had a relatively poor performance in predicting the nitrogen content of black soil affected by the nature of black soil itself.

(a)

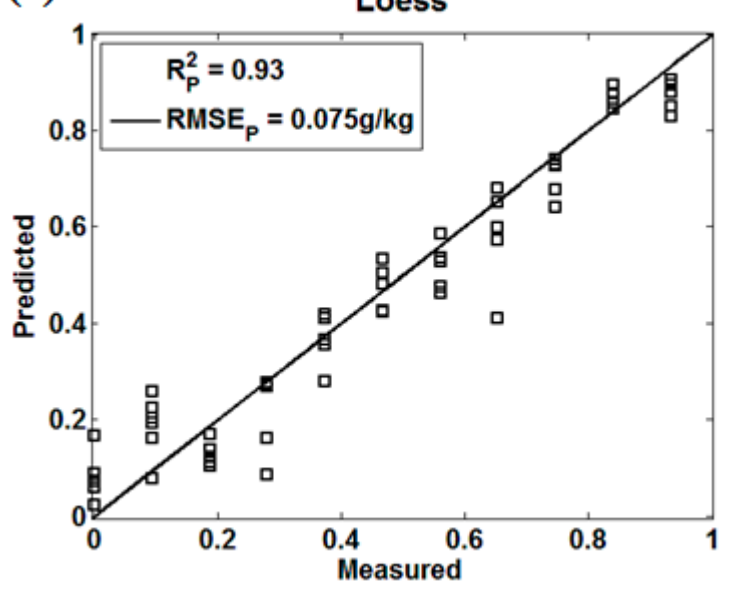

(c)

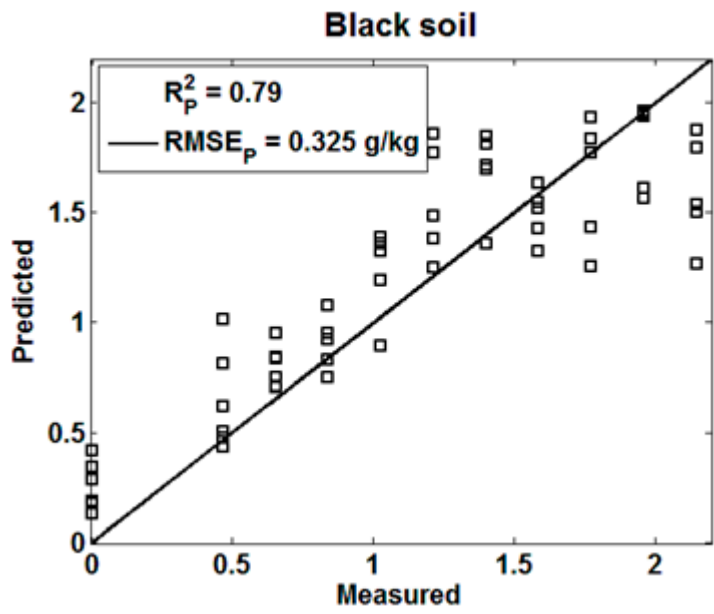

(b)

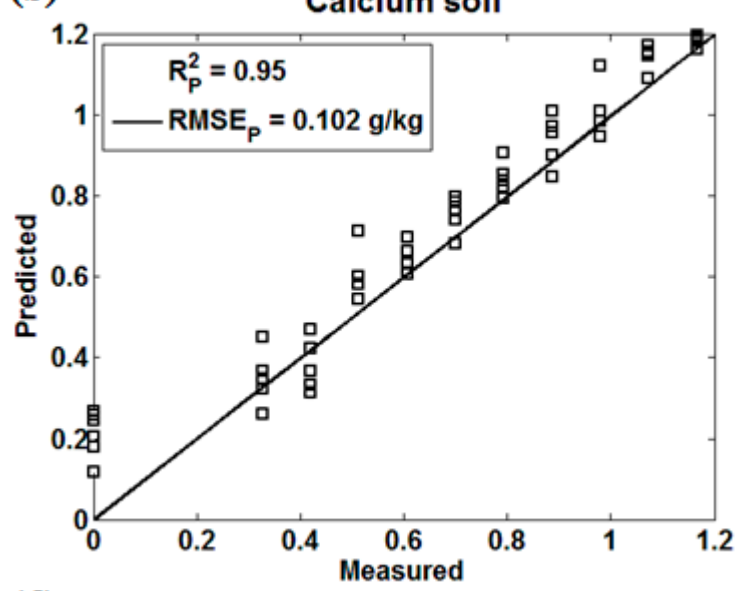

(d)

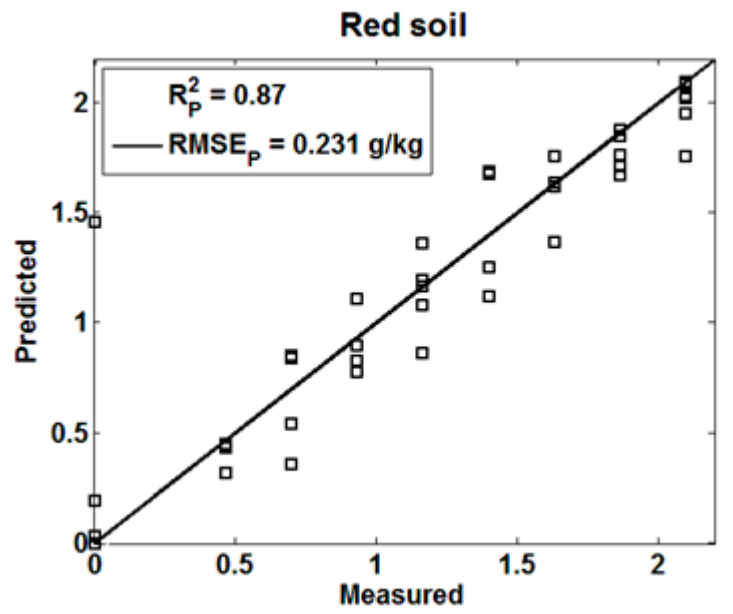

Figure 5. The Back Propagation Neural Network (BPNN) effect of four kinds of soils (a) Loess; (b) Calcium soil; (c) Black Soil; (d) Red soil.

\subsection{Sensitive Wavebands Selection}

\subsubsection{The Selection Process of Sensitive Wavebands}

In this paper, the CARS algorithm was used to select the characteristic variables of the NIR spectrum whose sampling times were set to 500, while the BIPLS algorithm was used to select the characteristic intervals. The red soil was an example to express the selection process of characteristic variables and characteristic intervals.

Figure 6a displays the selection process of characteristic variables carried by CARS. While running the CARS algorithm, the variables were selected by attenuation functions during each iteration and only the wavelength variables with large absolute values of PLS regression coefficients were preserved. According to the running results, the characteristic variables that occurred with high frequency were selected and grouped while running the CARS algorithm.

Figure $6 \mathrm{~b}$ shows the characteristic intervals of the soil spectrum selected by BIPLS and Figure $6 \mathrm{c}$ presents the best principal numbers determined by leave-one-out cross validation. Table 1 lists the variable selection results for BIPLS when the spectral intervals are divided into 20 segments. As the spectral intervals are gradually removed by BIPLS, the RMSECV values change constantly and the number of remaining intervals and variables in the model decrease. When the spectral interval of 
number 11 is removed, the RMSECV of the model reaches a minimum value of 0.233 , and the number of removed intervals is 14 . The remaining three intervals in the model are 13, 9, and 15, which have participated in the final modeling, and the number of variables in the model is 60 .

(a)

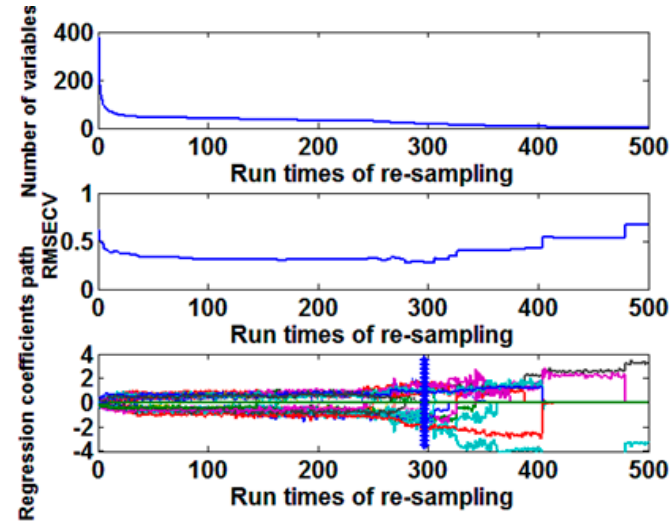

(b)

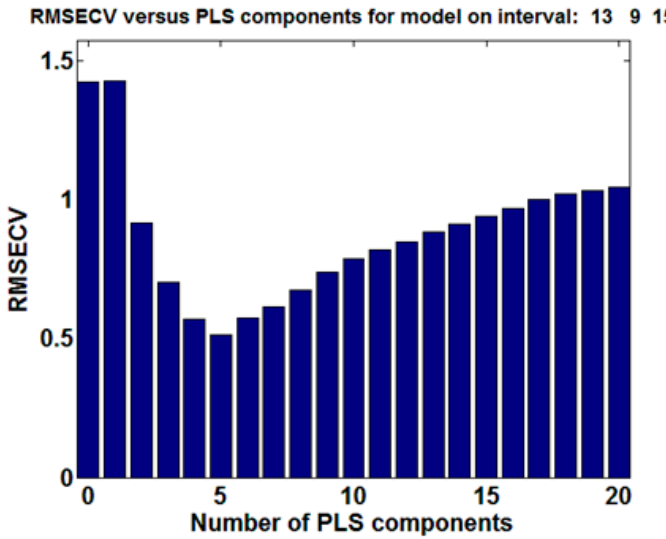

(c)

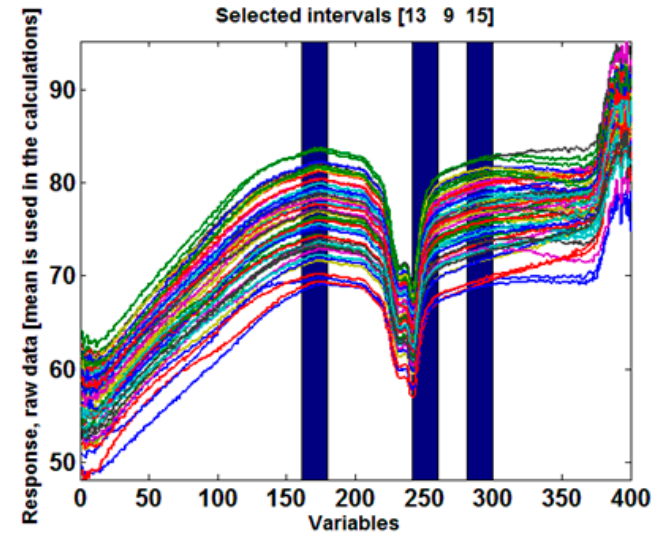

Figure 6. The sensitive waveband selection process (a) The characteristic variables selected by Competitive Adaptive Reweighted Sampling (CARS); (b) The number of PLS components and the corresponding Root Mean Square Error of Cross Validation (RMSECV) values while running BIPLS;

(c) The characteristic intervals determined by BIPLS.

Table 1. The processing results of characteristic variables by BIPLS.

\begin{tabular}{cccccccc}
\hline $\begin{array}{c}\text { Interval } \\
\text { Number }\end{array}$ & $\begin{array}{c}\text { Selected } \\
\text { Interval }\end{array}$ & RMSECV & $\begin{array}{c}\text { Variable } \\
\text { Numbers }\end{array}$ & $\begin{array}{c}\text { Interval } \\
\text { Number }\end{array}$ & $\begin{array}{c}\text { Selected } \\
\text { Interval }\end{array}$ & RMSECV & $\begin{array}{c}\text { Variable } \\
\text { Numbers }\end{array}$ \\
\hline 20 & 6 & 0.274 & 400 & 10 & 3 & 0.255 & 200 \\
19 & 16 & 0.270 & 380 & 9 & 1 & 0.255 & 180 \\
18 & 19 & 0.266 & 360 & 8 & 20 & 0.254 & 160 \\
17 & 7 & 0.265 & 340 & 7 & 12 & 0.246 & 140 \\
16 & 17 & 0.262 & 320 & 6 & 10 & 0.241 & 120 \\
15 & 8 & 0.256 & 300 & 5 & 11 & 0.236 & 100 \\
14 & 5 & 0.255 & 280 & 4 & 14 & 0.233 & 80 \\
13 & 4 & 0.254 & 260 & 3 & 13 & 0.240 & 60 \\
12 & 2 & 0.253 & 240 & 2 & 9 & 0.260 & 40 \\
11 & 18 & 0.254 & 220 & 1 & 15 & 0.435 & 20 \\
\hline
\end{tabular}

Intervals number, the number of intervals in the model; Selected interval, the interval selected by the BIPLS; RMSECV, root mean square error cross validation; Variable numbers, the number of variables in the model.

Table 2 presents the characteristic variables selected by CARS and the characteristic intervals selected by BIPLS of four kinds of soils. Linear correlation analysis was performed for each characteristic variable and each characteristic interval, and the results were sorted by correlation 
coefficients from the highest to the lowest. Finally, the characteristic variables and the characteristic intervals with high correlation were determined as the sensitive wavebands of soil according to the principle of the least number of variables and the best prediction effect. As a result, the determined sensitive wavebands were $1152 \mathrm{~nm}-1162 \mathrm{~nm}$ and $1296 \mathrm{~nm}-1309 \mathrm{~nm}$ (loess), $1036 \mathrm{~nm}-1055 \mathrm{~nm}$ and $1129 \mathrm{~nm}-1156 \mathrm{~nm}$ (calcium soil), $1055 \mathrm{~nm}, 1281 \mathrm{~nm}, 1414 \mathrm{~nm}-1428 \mathrm{~nm}$ and $1472 \mathrm{~nm}-1493 \mathrm{~nm}$ (black soil), $1250 \mathrm{~nm}, 1480 \mathrm{~nm}$ and $1680 \mathrm{~nm}$ (red soil).

Table 2. The selected characteristic variables, characteristic intervals, and sensitive wavebands.

\begin{tabular}{|c|c|c|c|c|}
\hline \multirow[b]{2}{*}{ Soil Type } & \multirow{2}{*}{$\begin{array}{c}\text { CARS Algorithm } \\
\text { Characteristic } \\
\text { Variables (nm) }\end{array}$} & \multicolumn{2}{|c|}{ BIPLS Algorithm } & \multirow[b]{2}{*}{$\begin{array}{l}\text { Sensitive Wavebands } \\
(\mathrm{nm})\end{array}$} \\
\hline & & $\begin{array}{l}\text { Characteristic } \\
\text { Intervals (nm) }\end{array}$ & $\begin{array}{c}\text { Serial Number of } \\
\text { Characteristic Interval }\end{array}$ & \\
\hline Loess & $1152-1162$ & $\begin{array}{c}1036-1078,1250-1329 \\
1411-1448,1487-1523, \\
1561-1596\end{array}$ & $4,8,9,10,13,15,17$ & $1152-1162,1296-1309$ \\
\hline Calcium Soil & 1129-1159 & $\begin{array}{c}900-944,1080-1290, \\
1525-1559\end{array}$ & $1,4,5,6,7,8,9,16,20$ & 1036-1055, 1129-1156 \\
\hline Black Soil & $\begin{array}{l}1414-1429 \\
1472-1493\end{array}$ & $\begin{array}{c}1036-1078,1250-1590 \\
1411-1559\end{array}$ & $4,9,12,13,14,15,16$ & $\begin{array}{c}1055,1281,1414-1428, \\
1472-1493\end{array}$ \\
\hline Red soil & $\begin{array}{c}1464-1469,1480, \\
1680\end{array}$ & $\begin{array}{c}1225-1290,1441-1447 \\
1486-1523\end{array}$ & $9,13,15$ & $1250,1480,1680$ \\
\hline
\end{tabular}

According to the Beer-Lambert law, the NIR spectrum varies with the variation of sample components and structure, and different groups generate different positions and intensities of spectral peaks [33]. Zhang et al. [12] selected six sensitive wavebands $(1375,1520,1861,2100,2286$, and $2387 \mathrm{~nm})$ for detecting soil nitrogen. Yang et al. [34] obtained the least collinear effective wavelength (820, 940, 1040,1060 , and $1990 \mathrm{~nm}$ ) of red soil using the successive projections algorithm (SPA) for variable selection. Kawamura et al. [2] suggested that the reflectance values at 1413 and 2207 nm were highly correlated with the soil's total carbon and total nitrogen contents. Although the determination of sensitive wavebands was influenced by soil type, detection instrument, and the spectral preprocessing method, it is partly similar in some waveband range. Therefore, it is of great application value to replace full wavebands with sensitive wavebands for improving the detection efficiency of soil nitrogen.

\subsubsection{Modeling Effect of Sensitive Wavebands}

The sensitive wavebands of four kinds of soils were determined combining the results of characteristic variables and characteristic intervals. The prediction effect of sensitive wavebands modeled by PLS is shown in Figure 7.

The PLS prediction model established by sensitive wavebands of four kinds of soils achieves relatively good prediction accuracy as well as full wavebands, especially for loess $\left(R_{p}^{2}=0.94, \mathrm{RMSE}_{p}=\right.$ $0.070 \mathrm{~g} / \mathrm{kg})$ and calcium soil $\left(R_{p}^{2}=0.91, \mathrm{RMSE}_{p}=0.104 \mathrm{~g} / \mathrm{kg}\right)$. The black soil $\left(R_{p}^{2}=0.83, \mathrm{RMSE}_{p}=\right.$ $0.270 \mathrm{~g} / \mathrm{kg}$ ) modeled by sensitive waveband performed better than that of PLS and BPNN but slightly worse than that of BIPLS. Both BIPLS and sensitive waveband partly eliminate the interference noise in the NIR spectrum of black soil, which enhances the prediction accuracy to a large extent. The prediction accuracy of red soil $\left(R_{p}^{2}=0.84, \mathrm{RMSE}_{p}=0.268 \mathrm{~g} / \mathrm{kg}\right)$ was slightly worse than that of PLS, BIPLS, and BPNN. Although the sensitive wavebands removed most of the interference noise, soil properties would affect the soil nitrogen detection using NIR sensors as well. However, the sensitive wavebands alternative is highly feasible to improve the modeling efficiency instead of the full-waveband spectrum, and it is a good prospect applicable to different soil types. 
(a)

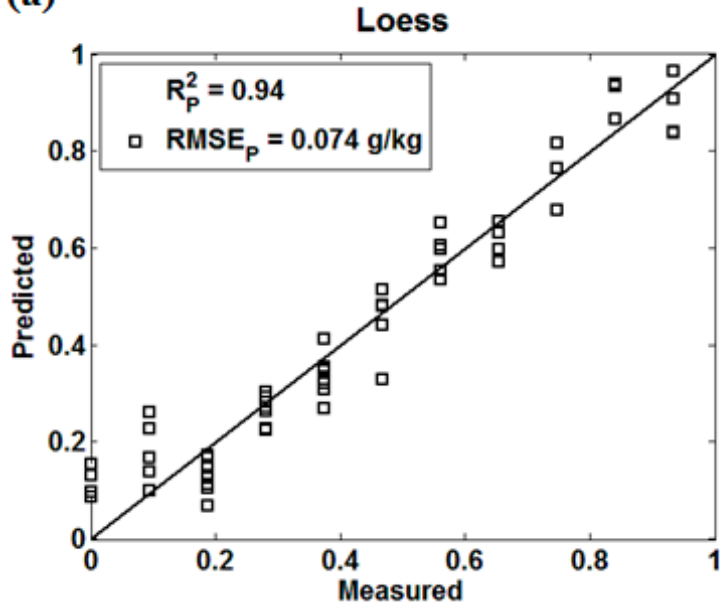

(c)

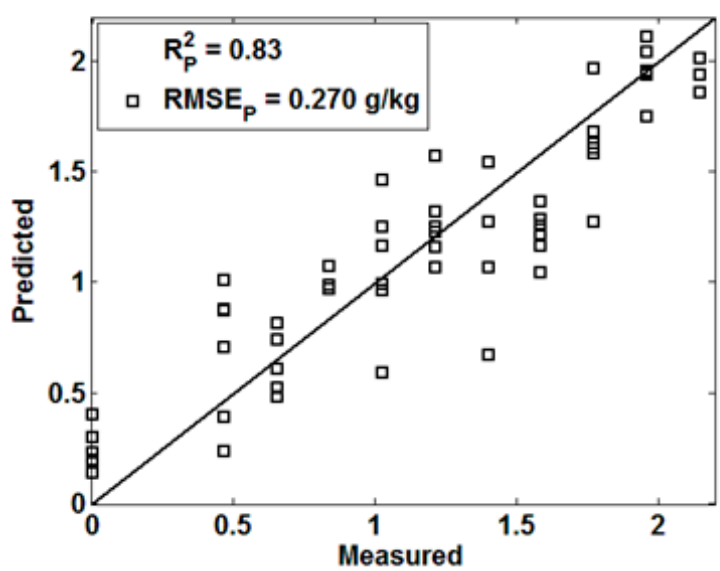

(b)

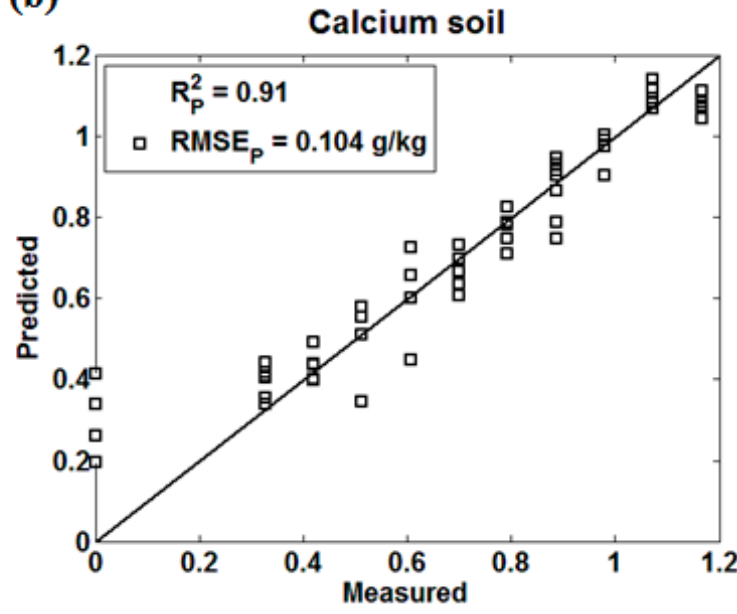

(d)

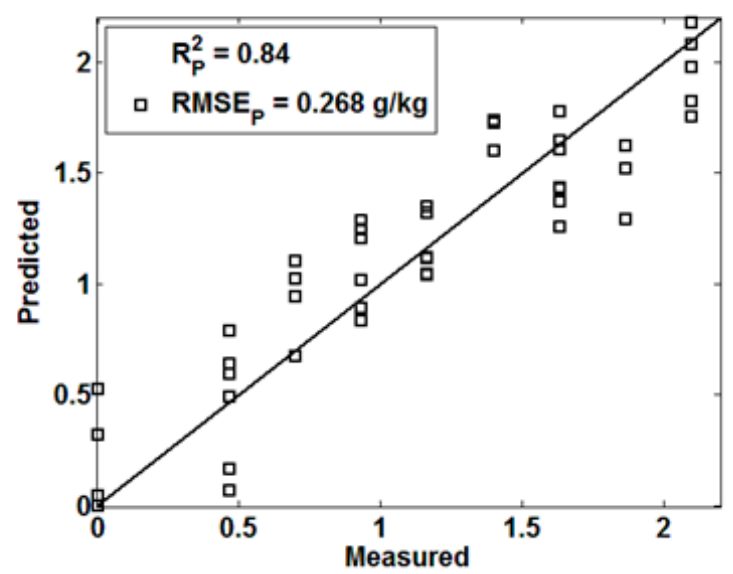

Figure 7. The sensitive waveband modeling effect of four kinds of soils (a) Loess; (b) Calcium soil; (c) Black Soil; (d) Red soil.

\subsection{Comparison of Modeling Effect}

In this experiment, PLS, BIPLS, and BPNN were used to establish the prediction model between the NIR spectrum and soil nitrogen content. CARS and BIPLS were used to determine the sensitive wavebands of four kinds of soils, and the prediction models of sensitive wavebands were established by PLS. In addition, the modeling effect of different soil types, different models, and sensitive wavebands were compared. The coefficient of determination $R^{2}$ and RMSE of the calibration set and prediction set are shown in Table 3.

From the perspective of soil properties, regardless of which prediction model (PLS, BIPLS, and BPNN) was used, both loess and calcium soil achieved good prediction accuracy. The reason is that the $\mathrm{N}-\mathrm{H}$ bonds in the soil mostly exist in multiple frequency or combination frequency, while the vibration of the $\mathrm{O}-\mathrm{H}$ and $\mathrm{C}-\mathrm{H}$ bonds is stronger than that of the $\mathrm{N}-\mathrm{H}$ bonds, which is one of the main factors affecting the NIR spectrum of soil nitrogen. The main components of loess are $\mathrm{SiO}_{2}, \mathrm{Al}_{2} \mathrm{O}_{3}$, and $\mathrm{CaO}$ while the main component of calcium soil is $\mathrm{CaCO}_{3}$ [35]. Both loess and calcium soil have few $\mathrm{O}-\mathrm{H}$ bonds after drying which interferes with the NIR spectrum to a large extent. Hence, the prediction accuracies of loess and calcium soil were the best among the four kinds of soils. The black soil and red soil obtained relatively low prediction accuracy compared with loess and calcium soil. Soil color reflects spectral characteristics in the visible light band, which is closely related to physical and chemical properties such as soil organic matter content, iron oxide content, texture, clay content, and moisture, which dominated clay mineral types [36]. The high humus content in black soil [37] 
and the strong absorption resulted in the worst prediction accuracy among the four kinds of soils. Although the color of red soil is not as dark as black soil, the high $\mathrm{Fe}(\mathrm{OH})_{3}$ and $\mathrm{Al}(\mathrm{OH})_{3}$ content in red soil [38] indicates more $\mathrm{O}-\mathrm{H}$ bonds. The strong vibration of $\mathrm{O}-\mathrm{H}$ bonds affected the vibration of the $\mathrm{N}-\mathrm{H}$ bonds in the soil, which resulted in a poor prediction effect as well.

From the perspective of algorithms, both loess and calcium soil achieved the highest $R_{p}^{2}(0.95$ and 0.96) and the lowest $\operatorname{RMSE}_{p}(0.066 \mathrm{~g} / \mathrm{kg}$ and $0.080 \mathrm{~g} / \mathrm{kg})$ in PLS models, indicating that PLS models could achieve a relatively good modeling effect for soils with less interference noise. The BIPLS model of black soil $\left(R_{p}^{2}=0.91, \operatorname{RMSE}_{p}=0.104 \mathrm{~g} / \mathrm{kg}\right)$ obtained the best prediction performance among the three algorithms, and it performed well in removing the interference noise caused by the strong absorption of black soil itself. The three models of red soil achieved similar prediction effects and reached the best performance in the BIPLS model as well as black soil, proving that BIPLS has a good effect on removing the interference noise and enhancing the prediction accuracy.

Table 3. The $R^{2}$ and RMSE values of four kinds of soils (loess, calcium soil, black soil and red soil) modeled by full wavebands (PLS, BIPLS, BPNN) and sensitive wavebands (PLS).

\begin{tabular}{|c|c|c|c|c|c|c|}
\hline \multirow[b]{2}{*}{ Soil Type } & \multirow[b]{2}{*}{ Model } & \multicolumn{2}{|c|}{ Calibration Set } & \multicolumn{3}{|c|}{ Prediction Set } \\
\hline & & $R_{c}^{2}$ & $\operatorname{RMSE}_{c}(\mathrm{~g} / \mathrm{kg})$ & $R_{p}^{2}$ & $\operatorname{RMSE}_{p}(\mathrm{~g} / \mathrm{kg})$ & $\begin{array}{c}\text { The Tested Range } \\
\text { (g/kg) }\end{array}$ \\
\hline \multirow{4}{*}{ Loess } & PLS & 0.95 & 0.066 & 0.95 & 0.066 & $0.057-0.944$ \\
\hline & BIPLS & 0.93 & 0.079 & 0.94 & 0.075 & $0.063-0.950$ \\
\hline & BPNN & 0.96 & 0.053 & 0.93 & 0.075 & $0.025-0.909$ \\
\hline & CARS/BIPLS-PLS & 0.92 & 0.080 & 0.94 & 0.074 & $0.041-0.972$ \\
\hline \multirow{4}{*}{ Calcium Soil } & PLS & 0.98 & 0.045 & 0.96 & 0.080 & $0.043-1.247$ \\
\hline & BIPLS & 0.95 & 0.074 & 0.95 & 0.081 & $0.018-1.173$ \\
\hline & BPNN & 0.96 & 0.038 & 0.95 & 0.102 & $0.101-1.196$ \\
\hline & CARS/BIPLS-PLS & 0.88 & 0.158 & 0.91 & 0.104 & $0.242-1.255$ \\
\hline \multirow{4}{*}{ Black Soil } & PLS & 0.98 & 0.086 & 0.79 & 0.285 & $0.079-2.149$ \\
\hline & BIPLS & 0.88 & 0.212 & 0.86 & 0.232 & $0.069-2.111$ \\
\hline & BPNN & 0.94 & 0.167 & 0.79 & 0.325 & $0.133-1.970$ \\
\hline & CARS/BIPLS-PLS & 0.85 & 0.249 & 0.83 & 0.270 & $0.240-2.112$ \\
\hline \multirow{4}{*}{ Red Soil } & PLS & 0.90 & 0.210 & 0.86 & 0.236 & $0.196-2.025$ \\
\hline & BIPLS & 0.87 & 0.239 & 0.86 & 0.231 & $0.028-2.133$ \\
\hline & BPNN & 0.95 & 0.158 & 0.87 & 0.231 & $0.019-2.090$ \\
\hline & CARS/BIPLS-PLS & 0.86 & 0.249 & 0.84 & 0.268 & $0.014-2.166$ \\
\hline
\end{tabular}

\section{Conclusions}

In this paper, the NIR spectral characteristics of loess, calcium soil, black soil, and red soil were investigated and three chemometric methods (PLS, BIPLS, and BPNN) were used to establish the prediction model between the NIR spectrum and soil nitrogen content. In addition, the sensitive wavebands of four kinds of soils were determined by BIPLS and CARS.

The principal results obtained can be summarized as follows: (1) The sensitive wavebands of four kinds of soils were determined, that is, $1152 \mathrm{~nm}-1162 \mathrm{~nm}$ and $1296 \mathrm{~nm}-1309 \mathrm{~nm}$ (loess), $1036 \mathrm{~nm}-1055 \mathrm{~nm}$ and $1129 \mathrm{~nm}-1156 \mathrm{~nm}$ (calcium soil), $1055 \mathrm{~nm}, 1281 \mathrm{~nm}, 1414 \mathrm{~nm}-1428 \mathrm{~nm}$ and $1472 \mathrm{~nm}-1493 \mathrm{~nm}$ (black soil), $1250 \mathrm{~nm}, 1480 \mathrm{~nm}$ and $1680 \mathrm{~nm}$ (red soil); (2) The prediction performance evaluated by $R^{2}$ and RMSE from good to bad was calcium soil $\left(0.95<R_{p}^{2}<0.96,0.080 \mathrm{~g} / \mathrm{kg}<\mathrm{RMSE}_{p}<0.102 \mathrm{~g} / \mathrm{kg}\right)$, loess $\left(0.93<R_{p}^{2}<0.95,0.066 \mathrm{~g} / \mathrm{kg}<\mathrm{RMSE}_{p}<0.075 \mathrm{~g} / \mathrm{kg}\right)$, red soil $\left(0.86<R_{p}^{2}<0.87,0.231 \mathrm{~g} / \mathrm{kg}<\right.$ $\left.\operatorname{RMSE}_{p}<0.236 \mathrm{~g} / \mathrm{kg}\right)$ and black soil $\left(0.79<R_{p}^{2}<0.86,0.232 \mathrm{~g} / \mathrm{kg}<\mathrm{RMSE}_{p}<0.325 \mathrm{~g} / \mathrm{kg}\right)$, and the $\mathrm{O}-\mathrm{H}$ bonds in soil might be the main factor influencing the prediction accuracy; (3) The PLS and BPNN models obtained a better prediction effect for soil with less noise, while BIPLS performed well in removing the interference noise caused by the strong vibration of $\mathrm{O}-\mathrm{H}$ or absorption of soil. 
Acknowledgments: This research was supported in part by National keypoint research and invention program of the thirteenth (2016YFD0700304) and Natural Science Foundations of China (Grant No. 61405175).

Author Contributions: Shupei Xiao and Yong He conceived the idea and designed the experiments; Shupei Xiao and Tao Dong performed the experiments; Shupei Xiao, Yong He and Tao Dong analyzed the data; Pengcheng Nie contributed the analysis tools and improved the data processing process; Shupei Xiao wrote the paper and all authors revised the paper.

Conflicts of Interest: The authors declare no conflict of interest.

\section{References}

1. Liu, W.D.; Baret, F.; Gu, X.F.; Tong, Q.X.; Zheng, L.F.; Zhang, B. Relating soil surface moisture to reflectance. Remote Sens. Environ. 2002, 81, 238-246.

2. Kawamura, K.; Tsujimoto, Y.; Rabenarivo, M.; Asai, H.; Andriamananjara, A.; Rakotoson, T. Vis-NIR Spectroscopy and PLS Regression with Waveband Selection for Estimating the Total C and N of Paddy Soils in Madagascar. Remote Sens. 2017, 9, 1081. [CrossRef]

3. Wu, D.; Chen, J.Y.; Lu, B.Y.; Xiong, L.; He, Y.; Zhang, Y. Application of near infrared spectroscopy for the rapid determination of antioxidant activity of bamboo leaf extract. Food Chem. 2012, 135, 2147-2156. [CrossRef] [PubMed]

4. Muñozhuerta, R.F.; Guevaragonzalez, R.G.; Contrerasmedina, L.M.; Torrespacheco, I.; Pradoolivarez, J.; Ocampovelazquez, R.V. A Review of Methods for Sensing the Nitrogen Status in Plants: Advantages, Disadvantages and Recent Advances. Sensors 2013, 13, 10823-10843. [CrossRef] [PubMed]

5. Ben-dor, E.; Banin, A. Near-infrared analysis as a rapid method to simultaneously evaluate several soil properties. Soil Sci. Soc. Am. J. 1995, 59, 364-372. [CrossRef]

6. Demattê, J.A.M.; Campos, R.C.; Alves, M.C.; Fiorio, P.R.; Nanni, M.R. Visible-nir reflectance: A new approach on soil evaluation. Geoderma 2002, 121, 95-112. [CrossRef]

7. Shao, Y.N.; He, Y. Nitrogen, phosphorus, and potassium prediction in soils, using infrared spectroscopy. Soil Res. 2011, 49, 166-172. [CrossRef]

8. He, Y.; Huang, M.; Annia, G.; Antihus, H.; Song, H.Y. Prediction of soil macronutrients content using near-infrared spectroscopy. Comput. Electron. Agric. 2007, 58, 144-153. [CrossRef]

9. Aitkenhead, M.J.; Coull, M.C.; Towers, W. Predicting soil chemical composition and other soil parameters from field observations using a neural network. Comput. Electron. Agric. 2012, 82, 108-116. [CrossRef]

10. Gao, H.Z.; Lu, Q.P.; Ding, H.Q.; Peng, Z.Q. Choice of characteristic near-infrared wavelengths for soil total nitrogen based on successive projection algorithm. Spectrosc. Spectr. Anal. 2009, 29, 2951-2954.

11. Rinnan, R.; Rinnan, A. Application of NIR reflectance (nir) and fluorescence spectroscopy to analysis of microbiological and chemical properties of arctic soil. Soil Biol. Biochem. 2007, 39, 1664-1673. [CrossRef]

12. Zhang, Y.; Li, M.Z.; Zheng, L.H.; Zhao, Y.; Pei, X.S. Soil nitrogen content forecasting based on real-time nir spectroscopy. Comput. Electron. Agric. 2016, 124, 29-36. [CrossRef]

13. Pan, T.; Wu, Z.H.; Chen, H.Z. Waveband optimization for near-infrared spectroscopic analysis of total nitrogen in soil. Chin. J. Anal. Chem. 2012, 40, 920-924. [CrossRef]

14. Dalal, R.C.; Henry, R.J. Simultaneous determination of moisture, organic carbon, and total nitrogen by NIR reflectance spectrophotometry. Soil Sci. Soc. Am. J. 1986, 50, 120-123. [CrossRef]

15. Lu, Y.L.; Bai, Y.L.; Wang, L.; Wang, H.; Yang, L.P. Determination for total nitrogen content in black soil using hyperspectral data. Trans. Chin. Soc. Agric. Eng. 2010, 26, 256-261.

16. Brunet, D.; Barthès, B.G.; Chotte, J.L.; Feller, C. Determination of carbon and nitrogen contents in alfisols, oxisols and ultisols from africa and brazil using nirs analysis: Effects of sample grinding and set heterogeneity. Geoderma 2007, 139, 106-117. [CrossRef]

17. Kuriakose, S.; Thankappan, X.; Joe, H.; Venkataraman, V. Detection and quantification of adulteration in sandalwood oil through NIR spectroscopy. Analyst 2010, 135, 2676-2681. [CrossRef] [PubMed]

18. Gorry, P.A. General least-squares smoothing and differentiation by the convolution (savitzky-golay) method. Anal. Chem. 1990, 62, 570-573. [CrossRef]

19. Chen, J.; Jönsson, P.; Tamura, M.; Gu, Z.H.; Matsushita, B.; Eklundh, L. A simple method for reconstructing a high-quality ndvi time-series data set based on the savitzky-golay filter. Remote Sens. Environ. 2004, 91, 332-344. [CrossRef] 
20. Hsu, H.; Binder, K.; Paul, W. How to define variation of physical properties normal to an undulating one-dimensional object. Phys. Rev. Lett. 2009, 103, 198301. [CrossRef] [PubMed]

21. Cramer, J.A.; Kramer, K.E.; Johnson, K.J.; Morris, R.E.; Rose-Pehrsson, S.L. Automated wavelength selection for spectroscopic fuel models by symmetrically contracting repeated unmoving window partial least squares. Chemom. Intell. Lab. Syst. 2008, 92, 13-21. [CrossRef]

22. Zhang, C.; Jiang, H.; Liu, F.; He, Y. Application of near-infrared hyperspectral imaging with variable selection methods to determine and visualize caffeine content of coffee beans. Food Bioprocess Technol. 2017, 10, $213-221$. [CrossRef]

23. Trygg, J.; Wold, S. Pls regression on wavelet compressed nir spectra. Chemom. Intell. Lab. Syst. 1998, 42, 209-220. [CrossRef]

24. Shi, J.Y.; Zou, X.B.; Zhao, J.W.; Mao, H.P. Selection of wavelength for strawberry nir spectroscopy based on bipls combined with saa. J. Infrared Millimeter Waves 2011, 30, 458-462. [CrossRef]

25. Zou, X.; Zhao, J.; Li, Y. Selection of the efficient wavelength regions in ft-nir spectroscopy for determination of ssc of 'fuji' apple based on bipls and fipls models. Vib. Spectrosc. 2007, 44, 220-227. [CrossRef]

26. Li, X.; He, Y.; Wu, C.; Sun, D. Nondestructive measurement and fingerprint analysis of soluble solid content of tea soft drink based on vis/nir spectroscopy. J. Food Eng. 2007, 82, 316-323. [CrossRef]

27. Liu, Y.; Sun, X.; Ouyang, A. Nondestructive measurement of soluble solid content of navel orange fruit by visible-nir spectrometric technique with plsr and pca-bpnn. LWT-Food Sci. Technol. 2010, 43, 602-607. [CrossRef]

28. Zhang, X.; Li, Q.; Zhang, G. Calibration transfer without standards for spectral analysis based on stability competitive adaptive reweighted sampling. Spectrosc. Spectr. Anal. 2014, 34, 1429-1433.

29. Parvinnia, E.; Sabeti, M.; Jahromi, M.Z.; Boostani, R. Classification of eeg signals using adaptive weighted distance nearest neighbor algorithm. J. King Saud Univ. Comput. Inf. Sci. 2014, 26, 1-6. [CrossRef]

30. Lindberg, W.; Persson, J.A.; Wold, S. Partial least-squares method for spectrofluorimetric analysis of mixtures of humic acid and lignin sulfonate. Anal. Chem. 1983, 55, 643-648. [CrossRef]

31. Zhang, J.J.; Tian, Y.C.; Yao, X.; Cao, W.X.; Ma, X.M.; Zhu, Y. The spectral index for estimating soil om, tn and an content simultaneously using near-infrared spectroscopy. Acta Pedologica Sin. 2012, 49, 50-59.

32. Esmaeili, R.; Dashtbayazi, M.R. Modeling and optimization for microstructural properties of al/sic nanocomposite by artificial neural network and genetic algorithm. Expert Syst. Appl. 2014, 41, 5817-5831.

33. Fuwa, K.; Valle, B.L. The physical basis of analytical atomic absorption spectrometry. The pertinence of the beer-lambert law. Anal. Chem. 1963, 35, 942-946. [CrossRef]

34. Yang, M.H.; Zhao, X.M.; Fang, Q.; Xie, B.Y. Study on Soil Total N Estimation by Vis-NIR Spectra with Variable Selection. Sci. Geog. Sin. 2014, 12, 2374-2383.

35. Hu, X.F.; Zhou, J.; Sun, Y.B.; An, Z.S. Different morphological features of the paleosols in the loess plateau, northwest china and their formations. Sci. Geog. Sin. 2000, 20, 39-44.

36. Sudduth, K.A.; Hummel, J.W. Soil organic matter, cec, and moisture sensing with a portable nir spectrophotometer. Trans. Asae 1993, 36, 1571-1582.

37. Zhang, W.L.; Xu, A.G.; Zhang, R.L.; Gong, H.J. Review of soil classification and revision of china soil classification system. Sci. Agric. Sin. 2014, 47, 3214-3230.

38. Huang, Y.Y.; Lin, S.R.; Yang, X.Y.; Chen, G.F.; Liu, B. Soil-forming conditions and ferrallisols formation features in guangxi. Southwest China J. Agric. Sci. 2008, 21, 1622-1625.

(C) 2018 by the authors. Licensee MDPI, Basel, Switzerland. This article is an open access article distributed under the terms and conditions of the Creative Commons Attribution (CC BY) license (http://creativecommons.org/licenses/by/4.0/). 